Coordenadores:

Luciano Lourenço

Fátima Velez de Castro

Pluralidade na

Diversidade

de Riscos

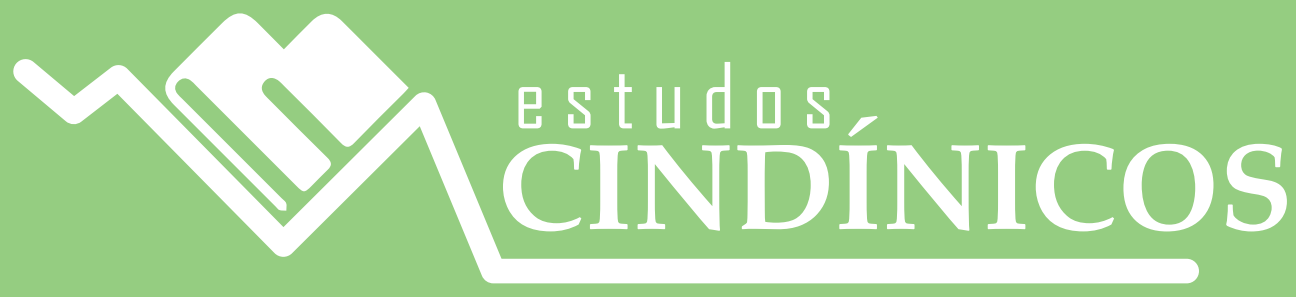

Riscos

Associação Portuguesa de Riscos, * Prevenção e Seguurança 
A "Pluralidade na diversidade de riscos" é uma obra composta por um conjunto de onze capítulos, cujos autores procuraram refletir aprofundadamente sobre uma multiplicidade de situações de risco, centradas na dimensão da avaliação, do aperfeiçoamento, da previsão e da mudança de paradigmas. Os trabalhos apresentados derivam da investigação científica realizada na área da formação, do clima e da sensação térmica, do ambiente e da psique. A partir da análise da diversidade fatual, pretende-se contribuir para aprimorar as respostas através da mitigação das falhas e de novas possíveis soluções.

É neste contexto territorial cada vez mais complexo, que urge olhar para a os riscos de forma plural e diversa, para que os estudos cindínicos possam manter o seu caráter inovador $\mathrm{e}$ utilitário, colocando-se ao serviço dos profissionais atuantes em momentos de risco, dos investigadores e, acima de tudo, das populações afetadas. 

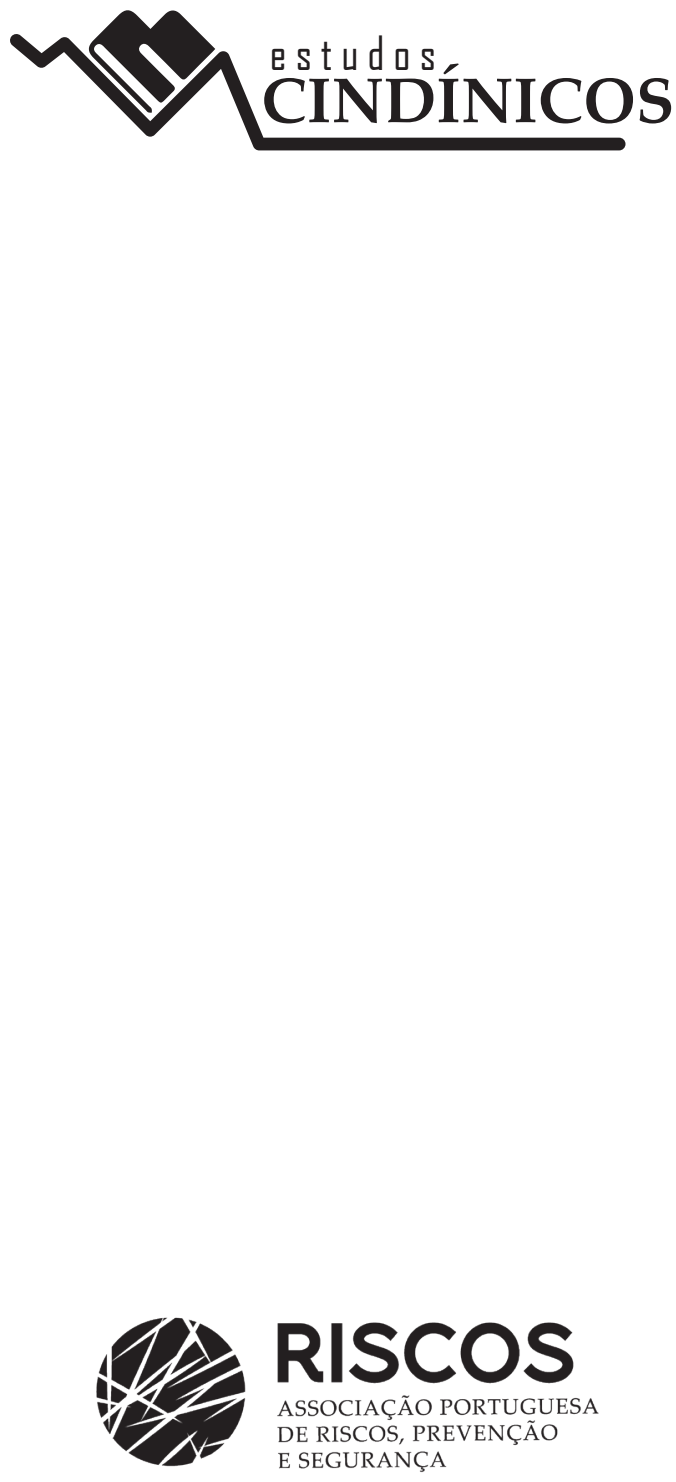


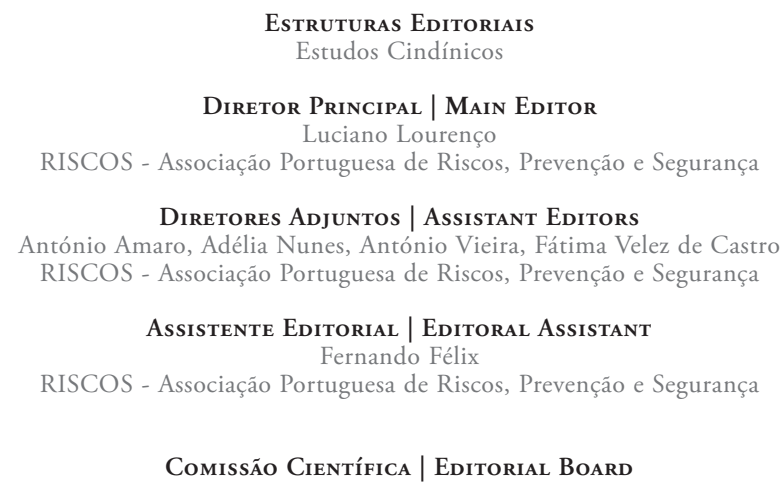

Ana Meira e Castro

Universidade do Porto

António Betâmio de Almeida

Instituto Superior Técnico, Lisboa

Cristina Queirós

Universidade do Porto

José Simão Antunes do Carmo

Universidade de Coimbra

Manuel João Ribeiro

Instituto Superior de Educaçáo e Ciências de Lisboa

Romero Bandeira

Instituto de Ciências Biomédicas Abel Salazar, Porto Universidade Distrital Francisco José de Caldas

Salvador Almeida

Universidade Lusófona do Porto
Carla Juscélia de Oliveira Souza

Universidade São Joâo del Rei

Maria Augusta Fernández Moreno

Católica do Equador

Miguel Castillo Soto

Universidade do Chile

Purificación Flaño

Universidade de La Rioja

Rita Cássia de Souza

Universidade Federal de Uberlândia

Yolanda Hernandez Peńa

Zeineddine Nouaceur

Universidade de Rouden

\section{Revisores Convidados | Invited Reviewers}

Adriana Panhol Bayma

Ministério do Meio Ambiente

António José Bento Gonçalves

Universidade do Minho

Eliana Marta Barbosa de Morais

Universidade Federal de Goiás

Helena Fernandez

Universidade do Algarve

Joáo Santos Baptista

Universidade do Porto

Lúcio Cunha

Universidade de Coimbra
Ney Roberto Váttimo Bruck

Universidade Federal de Pelotas

Roberto Lamberts

Universidade Federal de Santa Catarina

Rui Gama

Universidade de Coimbra

Teresa Durães Albuquerque

UInstituto Politécnico de Castelo Branco

Virgínia Maria Barata Teles

Universidade do Minho 
LUCIANO LOURENÇO

FÁTIMA VELEZ DE CASTRO

(COORDS.)

\section{PLURALIDADE NA DIVERSIDADE DE RISCOS}




\section{EDIÇÃo}

RISCOS - Associação Portuguesa de Riscos, Prevenção e Segurança

Email: riscos@riscos.pt

URL: https://www.riscos.pt/publicacoes/sec/

\section{Coordenaçáo Editorial}

Luciano Lourenço e Fátima Velez de Castro

\section{IMAGEM DA CAPA}

Karine Nieman

\section{Pré-IMPressáo}

Fernando Félix

\section{EXECUÇão GráficA}

Simôes \& Linhares, Lda.

ISSN

2184-5727

DOI (Série)

https://doi.org/10.34037/978-989-54295-1-6

\section{Depósito Legal \\ 449622/18}

ISBN

978-989-54295-5-4

ISBN Digital

978-989-54295-4-7

\section{DOI}

https://doi.org/10.34037/978-989-54295-4-7_5

\footnotetext{
${ }^{\circ}$ Dezembro 2018, RISCOS - Associação Portuguesa de Riscos, Prevenção e Segurança
} 


\section{SUMÁRIO}

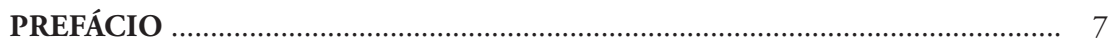

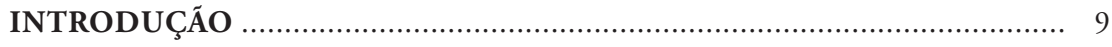

Avaliaçáo e adequação dos currículos de defesa civil dos cursos de formaçáo e aperfeiçoamento do corpo de bombeiros do rio de janeiro com vista à reduçáo do risco de desastres

Adriana Aparecida Bianchi Azevedo

O papel dos agrupamentos de corpos de bombeiros na mudança do paradigma da proteçáo civil municipal

Óscar Ferreira Catarino e António Duarte Amaro

Différences climatiques observées pour l'étude des précipitations et de la production de soja dans deux régions au Brésil

Vinicius Carmellos

Injustiça ambiental em um contexto industrial: Villa Hayes, Paraguai, como zona de sacrifício

Lidia Susana Tellez Ramos, Leo Name e Céline Veríssimo

Duas cançóes e o estresse pós-traumático

Altino Bessa Marques Filho e Victor Hugo Ferreira Silva

Como prever o isolamento térmico do vestuário para um ambiente térmico

Mário Talaia

As alteraçóes climáticas e a proteção civil

Nuno Gomes e Henrique Vicêncio

Bank erosion risks in Ouerrha catchment in northern Morocco: assessment and development issues

Mohammed El-fengour, Carlos Bateira, Abdelhak El-fengour, Abdelghani Houari and Mstafa Hmamouchi 


\section{SUMÁRIO}

Evoluçáo temporal (2009-2015) dos movimentos em massa na regiáo leste do estado de Sáo Paulo - Brasil

Geórgia Jorge Pellegrina, Anna Silvia Palcheco Peixoto e Ilza Machado Kaiser

As áreas de preservaçáo permanente e a sua importância na prevenção do risco (geomorfológico): estudo de caso em Santa Maria, RS, Brasil

Fernanda Maria Follmann, Franciele da Silva, Eliane Maria Foleto e Francisco

da Silva Costa

Riscos ambientais da exploração mineral na mina Pedra de Ferro-Caetité-BA

Altemar Amaral Rocha e Vaneusa Silva Pereira 


\section{PREFÁCIO}

Os riscos apresentam uma grande diversidade, quer nas causas que os podem originar, quer nas consequências que a sua manifestação pode determinar, pelo que só uma abordagem com pluralidade permite apresentar uma visão holística das múltiplas possibilidades de abordagem que os estudos dos riscos e das catástrofes proporcionam.

Ora, esta obra, em que são apresentadas várias perspetivas de análise, resulta precisamente de uma série de textos que, embora abordem temáticas diferentes, desde os riscos naturais aos antrópicos, e com estes materializados nos riscos tecnológicos e sociais, faz com que todos eles estejam ligados pelo mesmo fio condutor, que consiste em prevenir a sua manifestação, tomando as necessárias medidas de segurança, adequadas a cada tipo de risco, com o objetivo de reduzir os danos causados pelas suas manifestaçóes.

Mas, como todos sabemos, entre a teoria e a aplicação prática existe um longo caminho que é necessário ir percorrendo e a publicação deste volume constitui mais um pequeno passo, no sentido de divulgar situaçóes que poderiam ter sido evitadas ou, pelo menos, cujos efeitos poderiam ter sido bem mais reduzidos se houvesse uma melhor percepçáo do ricos e uma maior cultura de segurança.

Com efeito, o objetivo desta série é o de ir dando alguns pequenos passos, visando esse objetivo, através da edição regular de novas obras que, todos os anos, ajudem a alertar para situaçôes concretas de manifestaçôes de riscos.

Tendo em consideração que o ano de 2018 foi o de arranque desta nova coleção e que, com a publicação deste volume, foram dadas à estampa cinco obras, não podemos deixar de considerar que a série arrancou com fulgor e será desejável que, no próximo ano, possa manter o mesmo ritmo de publicação.

Para que isso aconteça e porque a série está aberta à colaboração de todos quantos se preocupam com os riscos e as suas manifestaçóes, sejam eles e elas associados ou náo da RISCOS, contamos receber propostas para publicar livros nesta série, de modo a que ela possa ser útil a todos quantos pretendem reduzir os efeitos das catástrofes.

Coimbra, 30 de novembro de 2018. 



\section{INTRO DUÇÃO}

Fátima Velez de Castro

Departamento Geografia e Turismo, CEGOT e RISCOS, Universidade de Coimbra (Portugal) ORCID: 0000-0003-3927-0748 velezcastro@fl.uc.pt

Fernando Rebelo (2010), numa das suas obras derradeiras, onde sistematizou o desenvolvimento da relação entre a Geografia Física e os Riscos Naturais ${ }^{1}$, ao invocar o contributo dos geógrafos percursores do estudo destes fenómenos em Portugal, deixou a seguinte reflexão:

"No entanto, se as observaçôes "em cima do acontecimento" foram importantes para muitos geógrafos, foi quase sempre através do estudo de situaçōes de crise acabadas de ocorrer que puderam deduzir como elas, frequentemente, resultavam da evolução de situações de perigo, que talvez pudessem ser evitadas" (Rebelo, 2010, p. 28).

Nesta obra intitulada "Pluralidade na diversidade de riscos", agrupa-se um conjunto de capítulos, derivados do esforço de investigação científica de vários autores que, na sua essência, expressam essa mesma preocupação, ou seja, a de refletir aprofundadamente sobre uma multiplicidade de situaçóes de risco, assim como as formas de mitigação. Tendo em conta as palavras componentes dos vários títulos enunciados, percebe-se a natureza do objetivo desta obra, centrada em quatro ações principais, a saber: avaliar, aperfeiçoar, mudar paradigmas, prever. No fundo, partir da diversidade fatual das causas das situaçóes, pretende-se refletir sobre as formas de aprimorar as respostas através da mitigação das falhas, assim como de novas possíveis soluções. É nesta lógica epistemológica que, por um lado, se poderão corroborar e aperfeiçoar paradigmas; por outro, repensá-los numa lógica de mudança e de inovação.

\footnotetext{
${ }^{1}$ Rebelo, F. (2010), Geografia Fisica e Riscos Naturais. Coimbra: Imprensa da Universidade de Coimbra.
} 
Os trabalhos aqui apresentados organizam-se em torno de quatro áreas temáticas, nomeadamente a formação; o clima e a sensação térmica; o ambiente; a psique.

No que diz respeito à formação, Adriana Azevedo apresenta um estudo em que pretende avaliar a adequação dos currículos de defesa civil para o corpo de bombeiros do rio de janeiro, tendo em vista a redução do risco de desastres. A sua pesquisa incidiu em cursos ministrados pela Escola Superior de Comando de Bombeiro Militar a na Academia de Bombeiro Militar D. Pedro II, através do levantamento das ementas, grade curricular e planos de sessão, sendo a metodologia utilizada de cariz empírico-analítico, com base na análise comparativa.

Já Óscar Catarino e António Amaro procuraram refletir sobre a mudança de paradigma da proteçáo civil municipal, tendo em conta o papel dos agrupamentos de corpos de bombeiros, no que diz respeito às respostas ao socorro dadas à população. Metodologicamente, os autores optaram pelo estudo de caso dos agrupamentos dos corpos de bombeiros de Mafra e Espinho, tendo sido realizadas entrevistas semiestruturadas, que serviram de base a uma análise de conteúdo.

Sobre a questão do clima e da sensação térmica, dois capítulos abordam áreas temáticas de interesse. Vinicius Carmellos compara a variabilidade das chuvas durante o cultivo da soja, tendo como referência o período temporal compreendido entre 1998-1999 e 2012-2013. A sua pesquisa centra-se na região noroeste do Rio Grande do Sul e na região Norte do Mato Grosso. O autor optou por uma abordagem estatística, analisando os dados mensais totais acumulados entre outubro e abril dos anos propostos, com posterior cálculo da correlação multivariada entre os fatores de precipitação, superfície cultivada e quantidade produzida.

Nuno Gomes e Henrique Vicêncio apresentam os resultados de um trabalho de investigação, cujo objetivo se centrou no estudo do grau de envolvimento dos municípios portugueses do continente, na problemática das alteraçóes climáticas, além de analisarem os modos de articulação com a administração central, em especial com os organismos responsáveis pela proteção civil. Os autores basearam os procedimentos metodológicos num questionário em plataforma virtual (Google), o qual foi respondido por 278 Câmaras Municipais.

No que concerne à dimensão da sensação térmica, Mário Talaia analisou o conforto térmico, tendo em conta as condiçóes termohigrométricas resgistadas em am- 
biente específico. Com base na validação de um método de cálculo de isolamento térmico de vestuário, o autor intersecciona fatores como a temperatura do ar, a temperatura do termómetro húmido, entre outros, para perceber o nível de conforto dos intervenientes, na relação entre o contexto de exposição e o vestuário usado.

No que diz respeito ao ambiente, Geórgia Pellegrina, Anna Peixoto e Machado Kaiser, realizaram uma evolução temporal dos movimentos de massa na região leste do estado de S.Paulo, no Brasil, no período temporal de 2009 a 2015. Os autores pretenderam averiguar a relaçáo entre a pluviosidade, a ocorrência de movimentos de massa, a densidade populacional e o número de indivíduos afetados. Do ponto de vista do método de trabalho, foram numeradas as ocorrências dos três períodos mais críticos do tempo em estudo, tendo sido a distribuiçẫo espacial das ocorrências e de suas vítimas comparadas com as precipitações normalizadas em função das normais pluviométricas e da densidade populacional dos municípios.

Já Fernanda Follmann, Franciele da Silva, Eliane Foleto e Francisco Costa, discutiram a importância das áreas de preservação permanente na prevenção do risco geomorfológico, na microbacia hidrográfica de Chácara das Flores, Em Santa Maria, Rio Grande do Sul, Brasil. O método utilizado permitiu combinar a cartografia da área em estudo com o mapa das áreas de risco geomorfológico.

Também Mohammed El-Fengour, Carlos Bateira, Abdelhak El-Fengour, Abdelghani Houari e Mstafa Hmamouchi apresentam um trabalho sobre os processos hidroerosivos nas Montanhas do Rif, em Marrocos, e de como este tipo de risco está a afetar as infraestruturas e territórios adjacentes (redes viárias, terrenos agrícolas, etc), com as consequências socio-económicas conexas. Para realização do estudo, os autores recorreram a fotografias aéreas, cartografia, assim como ao cálculo "cumulative rainfall'.

Valdemar Rocha e Vaneusa Pereira abordam o tema da exploração mineral no Maciço do Espinhaço, na Bahia, Brasil, dando conta dos riscos ambientais associados, assim como das alteraçôes sócio-espaciais decorrentes, nomeadamente no que respeita ao acesso aos recursos hídricos. A metodologia usada baseou-se na recolha de dados em contexto de trabalho de campo, pela observaçáo direta, assim como por captação de imagens fixas e realizaçáo de questionários por entrevista e por inquérito. 
Lídia Ramos, Leo Name e Céline Veríssimo dão visibilidade ao caso de Vila Hayes, no Paraguai, refletindo sobre as injustiças ambientais e de como estas mais afetam populaçôes vulneráveis, com fragilidades económicas e sociais. Os autores agruparam e discutiram um vasto conjunto de dados, reforçando o papel dos geógrafos enquanto ativistas e promotores da justiça social, dando voz à situação periclitante de comunidades de/em risco.

Por fim, a dimensão da psique está plasmada no capítulo de Altino Filho e Vitor Silva, que abordaram a questáo do transtorno de stress pós-traumático, enfatizando o papel da música como ferramenta que coloca em evidência as angústias e os traumas da sociedade moderna. Tendo como base duas letras de cançôes, os autores realizaram uma análise de conteúdo, procurando evidenciar o benefício desta arte como difusora da dinâmica patológica em causa e, em certa medida, desconstruir os estereótipos em torno dos transtornos mentais.

Num contexto territorial cada vez mais complexo, é urgente olhar para a os riscos de forma plural e diversa, para que os estudos cindínicos possam manter o seu caráter inovador e utilitário, colocando-se ao serviço dos profissionais atuantes em momentos de risco, dos investigadores e, acima de tudo, das populaçóes afetadas. 


\title{
INJUSTIÇA AMBIENTAL EM UM CONTEXTO \\ INDUSTRIAL: VILLA HAYES, PARAGUAI, COMO ZONA DE SACRIFÍCIO
}

\author{
ENVIRONMENTAL INJUSTICE IN AN INDUSTRIAL \\ CONTEXT: VILLA HAYES, PARAGUAY, \\ AS A SACRIFICIAL ZONE
}

\begin{abstract}
Lidia Susana Tellez Ramos
Universidade Federal da Integração Latino-Americana (Brasil) ORCID: 0000-0003-4900-6641 lidia.ramos@aluno.unila.edu.br
\end{abstract}

Leo Name

Universidade Federal da Integração Latino-Americana (Brasil) ORCID: 0000-0002-1963-1094 leonardo.name@unila.edu.br

Céline Veríssimo

Universidade Federal da Integração Latino-Americana (Brasil) ORCID: 0000-0002-2967-9964 celine.verissimo@unila.edu.br

Resumo: Objetivamos dar visibilidade ao debate a respeito das injustiças ambientais muitas vezes ignoradas nos contextos hispano-americanos. Como estudo de caso, apresentaremos Villa Hayes, cidade paraguaia, dando ênfase na implantação massiva e progressiva de indústrias nesta cidade nos últimos anos, o que, além de ampliar diferentes situaçôes de risco, para nós, a caracteriza como uma zona de sacrifício.

Palavras-chave: Justiça ambiental, riscos, zonas de sacrifício. 


\begin{abstract}
In order to draw attention to the debate about environmental injustice that often is ignored in Spanish-American contexts, we present the case study of Villa Hayes, a Paraguayan city. We focus on the steady locating of industries in this city in recent years which we believe not only expands different risk situations, but also characterizes the city as a sacrificial zone.
\end{abstract}

Keywords: Environmental injustice, environmental risks, sacrificial zone.

\title{
Introdução
}

Faz mais de vinte anos que a Organização das Naçóes Unidas (ONU, 1994) determinou que toda pessoa tem direito a um meio ambiente adequado, considerado uma condição prévia para outros direitos: à vida, à saúde e à alimentação. No entanto, particularmente nos países do Sul Global - e em especial para o tema deste trabalho, da América latina - as cidades contam com problemas ambientais de grande magnitude, o que demanda uma dupla reflexáo: por um lado, sobre o planejamento urbano e a aplicação dos marcos normativos que deveriam velar pelo bem-estar das populaçóes e instituir o equilíbrio entre a utilização e a proteção do meio ambiente; por outro, sobre quais são os grupos mais prejudicados pelos danos ambientais.

Em relação ao primeiro ponto, é indispensável avaliar a existência e a eficiência das políticas públicas adotadas pelo Estado para combater os impactos ambientais, muitas vezes irreversíveis. No caso das cidades latino-americanas, elas têm sido submetidas, pelo menos desde a década de 1990, a um certo pensamento conservador que, ao anunciar uma crise do planejamento, propóe novas perspectivas (Borja e Castells, 1998; de Souza, 2001; Novaes, 2010): competição entre cidades, flexibilidade de parâmetros legais e benefícios e facilidades para a implantação de empreendimentos privados. Essa visão afirma que quaisquer passivos ambientais de quaisquer projetos podem ser evitados desde que utilizados os incentivos para a inovação e a criatividade, ambos impulsionados pela chamada "modernização ecológica".

A respeito da segunda questão, não existem dúvidas que, sob a atual produção do espaço urbano e as lógicas de controle territorial dominantes, as classes mais 
abastadas disfrutam da maioria dos atrativos e amenidades ambientais, enquanto que aos pobres são direcionados os piores efeitos do processo de urbanizaçáo e industrialização. Para descrever tais situaçôes, a literatura acadêmica, usualmente vinculada à ecologia política, tem direcionado atenção para temáticas que, ao darem enquadramento analítico aos conflitos e mobilizaçôes relacionados ao meio ambiente, afirmam existir "mau desenvolvimento" (derivado dos insustentáveis modelos econômicos e territoriais vigentes); "injustiças ambientais" (relacionadas ao acesso muito desigual aos recursos naturais e ecossistêmicos, como à distribuiçấo iníqua das externalidades negativas e dos riscos ambientais entre os diferentes estratos sociais); e, finalmente, "zonas de sacrificio" (seja nas escalas internacional, inter-ou intraurbana, trata-se das áreas que são sacrificadas para receber massiva superposição de empreendimentos, usos ou atividades responsáveis por severos danos ambientais e riscos sociossanitários (cf. Acselrad et al., 2009; Bullard, 1994; da Silva e Bueno, 2013; Escobar, 1995, 2007; Martínez-Alier, 2002, 2007; Name e Bueno, 2013; Porto, 2007; Svampa e Viale, 2014; Viégas, 2006)).

Uma análise deste panorama de injustiças ambientais no contexto hispanoamericano implica ampliar o debate para além dos Estados Unidos, onde surgiu o movimento por justiça ambiental; e no Brasil, onde a produção acadêmica a este respeito é mais forte que em seus vizinhos de subcontinente. No Paraguai, por exemplo, tal discussão é praticamente inexistente, na esfera política ou acadêmica, ainda que a realidade de suas cidades, sobretudo as do interior do país, exija esse aprofundamento teórico.

Perante isto, neste trabalho apresentaremos Villa Hayes, capital do departamento paraguaio de Presidente Hayes, na regiāo do Chaco, como um estudo de caso de zona de sacrifício: numa localidade de frágeis e escassos indicadores ambientais, sistemas de controles e instrumentos normativos, deu-se uma progressiva e massiva implantação de dezesseis indústrias, às quais se vinculam vários riscos para o meio ambiente e para a saúde humana. Muitas destas indústrias estão localizadas nas margens do rio Paraguai, uma área ambientalmente protegida. Neste trabalho, utilizaremos dados da Direção Geral de Estatísticas, Encostas e Censos (DGEEC). Trata-se da instituiçáo nacional responsável pela coleta e análise de dados sobre as populaçôes e territórios paraguaios. Estes censos e pesquisas são geralmente ajustados 
à escala nacional ou por departamento, mas infelizmente sua periodicidade é intermitente, não formando séries históricas - um problema comum das estatísticas no Paraguai. Especificamente sobre Villa Hayes, os dados mais recentes são os do ano 2003. Justamente por isso, nossa análise será cotejada com certa literatura sobre as redes urbanas do Paraguai, um mapeamento das atividades poluidoras e seus possíveis impactos em Villa Hayes e informaçôes da imprensa e denúncias em sítios da internet que relataram a preocupação da sociedade civil com os ricos das atividades industriais nessa localidade.

\section{A produção de injustiças ambientais}

O planejamento urbano náo tem enfrentado as transformaçóes que experimentam as cidades e que produzem diferenças espaciais extremas. Ao contrário, parece reforçar os processos nos quais determinadas classes sociais saem beneficiadas sobre outras, ao mesmo tempo que também naturaliza um único caminho em direção ao "desenvolvimento". Assim, normalmente sob uma lógica econômica estrita, são implementadas grandes obras de infraestrutura e autorizados grandes empreendimentos, equipamentos e instalações, inclusive industriais, que produzem ou ampliam danos ambientais - exploração massiva de recursos naturais renováveis e não renováveis, poluição do ar, vazamentos químicos ou de petróleo; destruição do solo e contaminação da água; desertificação; e ameaças à flora e a fauna. Nesse contexto, o bem comum que é a natureza é expropriado por interesses privados que, ao utilizarem extensivamente seus recursos, devolvem por sua vez os detritos de sua produção (fig. 1).

A despeito desta clara injustiça, a resolução dos problemas ambientais ainda é condicionada às necessidades das empresas, isto é, limitando-os à solução da escassez de matéria e energia e considerando-os tanto uma oportunidade de negócios como uma maneira do mercado redefinir-se como "ecologicamente responsável”. Aderindo às falsas promessas da "economia verde" (Moreno, 2013), Estado e empresa propóem a conciliação do crescimento econômico com a utilização de tecnologias "limpas" e outras ferramentas de mercado, supostamente capazes de mediar os efeitos danosos 


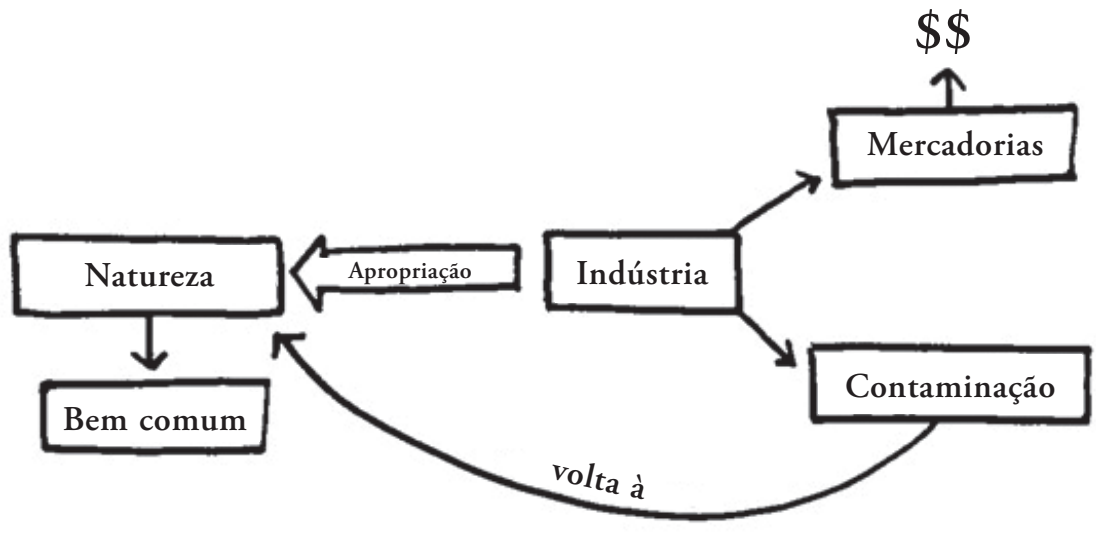

Fig. 1 - Lógica capitalista de expropriação da natureza e uso de seus recursos.

Fig. 1 - Capitalist logic of expropriation of nature and use of its resources.

da produção econômico-industrial e sua consequente ocupação dos territórios. No entanto, ignora-se que as tecnologias não são uniformes nem tampouco acessíveis em todos contextos geo-históricos e por todos os grupos sociais - e que nem sequer são efetivamente limpas. Assim,

\section{"[...] ainda que na atualidade exista uma tendência de quantificar $e$} compensar os danos ao meio ambiente, o impacto que uma atividade como a petroleira ou mineira produz sobre o ecossistema e à saúde humana, o que significam em termos de redução da biodiversidade e desaparecimento de culturas e estilos de vida, é algo incomensurável' (Svampa e Viale, 2014, p. 82).

Não é segredo que "é para as regióes pobres que se tem dirigido empreendimentos econômicos mais danosos em termos ambientais" (Acselrad et al., 2009, p. 8). A visão de desenvolvimento, abordada a partir de seu caráter meramente econômico, apenas assegura a liberdade às concepçóes e projetos do mercado que geram mais lucro, sem que importem os custos à coletividade e as desigualdades. É para combater esta situação - na qual a economia se torna mais importante que a vida -, além de trazer à luz os aspectos político-sociais que situam como protagonista a população que é vítima dos processos ambientalmente impactantes, que é concebida a justiça ambiental. Trata- 
se de uma abordagem que vem afirmando ser imprescindível compreender que não se enfrenta a crise ambiental sem que se exponha, debata e combata a correlaçáo da degradaçáo do meio ambiente e os problemas sociais com a racionalidade capitalista, a qual concentra lucros e designa custos desigualmente (Name e Bueno, 2013). O combate às injustiças ambientais se dá com vistas a se garantir que nenhum grupo social - de diferença racial, étnica ou de classe - suporte cargas desproporcionais das consequências ambientais negativas dos processos, programas, políticas e projetos voltados ao "desenvolvimento" (Acselrad et al., 2009, p. 4).

A justiça ambiental é simultaneamente uma abordagem teórica e uma bandeira política, que refuta a ideia de que todas as pessoas são igualmente vulneráveis aos riscos ambientais. Além disso, clarifica os processos que criam e mantêm "territórios convertidos em áreas de sacrificio, nas quais os corpos e até mesmo as vidas são considerados descartáveis e sacrificáveis" (Svampa e Viale, op. cit., p. 84). Finalmente, sobre a defesa de que as indústrias representam fontes de trabalho, recorda-nos que estas também representam riscos e danos no curto, médio e longo prazos. A extração e degradação massiva dos recursos naturais, o uso e despejo contaminantes - químicos, térmicos, radiativos - que afetam a biodiversidade e a saúde humana, principalmente das populaçôes cuja vulnerabilidade econômica as força a viver em áreas próximas às fontes de contaminação (fig. 2).

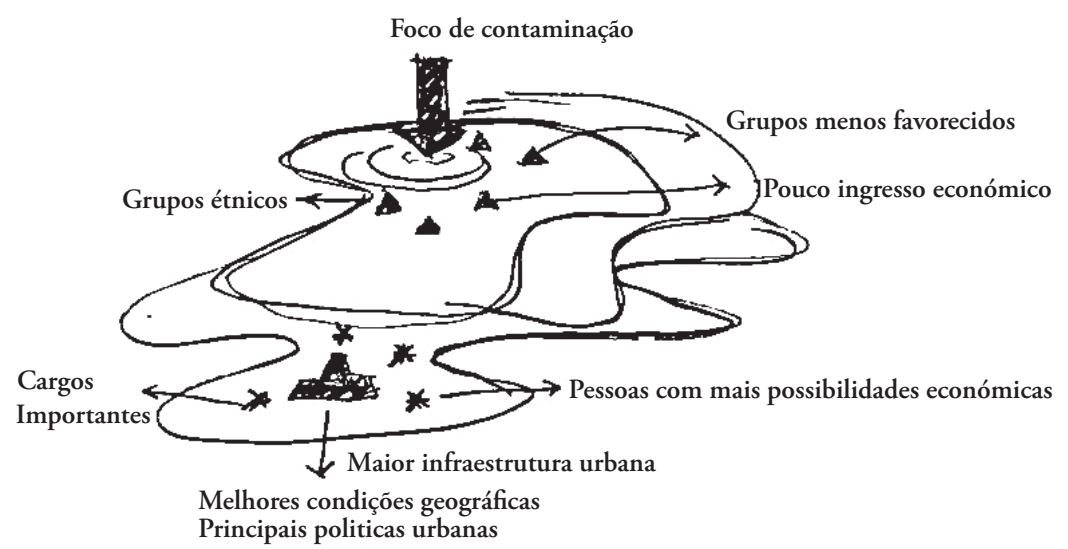

Fig. 2 - A distribuição desigual dos riscos ambientais.

Fig. 2 - The uneven distribution of environmental risks. 
Nas atividades industriais, é permanente o risco à saúde, o qual pode ser definido como a exposição de seres humanos a condiçóes ambientais adversas e capazes de gerar sofrimento, doenças e mortes - que não ocorreriam ou teriam a mesma gravidade, caso a exposição não ocorresse (Porto, 2007, p. 96). Por conseguinte, no que tange à problemática dos riscos, não há acidentes: prevalecem a negligência e a injustiça.

\section{Villa Hayes como uma zona de sacrifício}

Sem dúvida as atividades agrícolas, extrativas e industriais de longa data têm relevância na economia de muitos países latino-americanos. Ainda que frequentemente tenham contribuído para a transformaçáo urbana vinculada ao crescimento econômico, é seguro dizer que várias vezes, também, foram os principais responsáveis pela destruição e contaminação do meio ambiente.

O Paraguai fundou sua economia produtiva coadunada com a existência de grandes latifúndios, a maioria com capitais estrangeiros. No país, $2 \%$ das propriedades ocupam $85 \%$ das terras e as transnacionais são destinadas na atividade primária de produção de soja e algodáo, estendendo-se, pouco a pouco, a outros setores (Peralta e Perrotta, 2004, p. 186).

Nesse contexto, as duas grandes guerras internacionais com alta mortandade da população- a guerra contra a Tríplice Aliança, em torno de conflitos territoriais com o Brasil, a Argentina e o Uruguai na segunda metade do século XIX; e a Guerra do Chaco, relacionada a conflitos com a Bolívia na década de 1930 - e uma longa ditadura militar entre 1954 e 1989, além dos traços culturais de preeminência rural e da inexistência de correntes sistemáticas e duradouras de imigraçáo estrangeira foram alguns dos fatores que fizeram com que, à exceção de Assunção, tenham demorado a surgir grandes centros urbanos de relevância (Vásquez, 2010 e 2013). Foi somente no ano de 1992 em que o Paraguai, pela primeira vez, apresentou uma maioria de habitantes vivendo em cidades. O crescimento urbano foi uma consequência do período anterior de dez anos, quando sua população urbana aumentou em mais de 700 mil habitantes, em geral oriundos de migraçôes internas no país. Por um lado, nesse processo se destacaram cidades fronteiriças como 
Encarnaçáo e Ciudad del Este - refletindo a dependência a países vizinhos; por outro, formou-se um novo sistema urbano ainda centrado em Assunção (Vázquez, 2013), do qual atualmente participam as cidades do Chaco próximas às fronteiras com o Brasil e a Argentina - quer cidades médias como pequenas, como é o caso de Villa Hayes (fig. 3).

Villa Hayes é a capital do XV Departamento Presidente Hayes e possui 47.156 $\mathrm{km}^{2}$ de extensão territorial - a mais ampla entre os distritos existentes - sendo

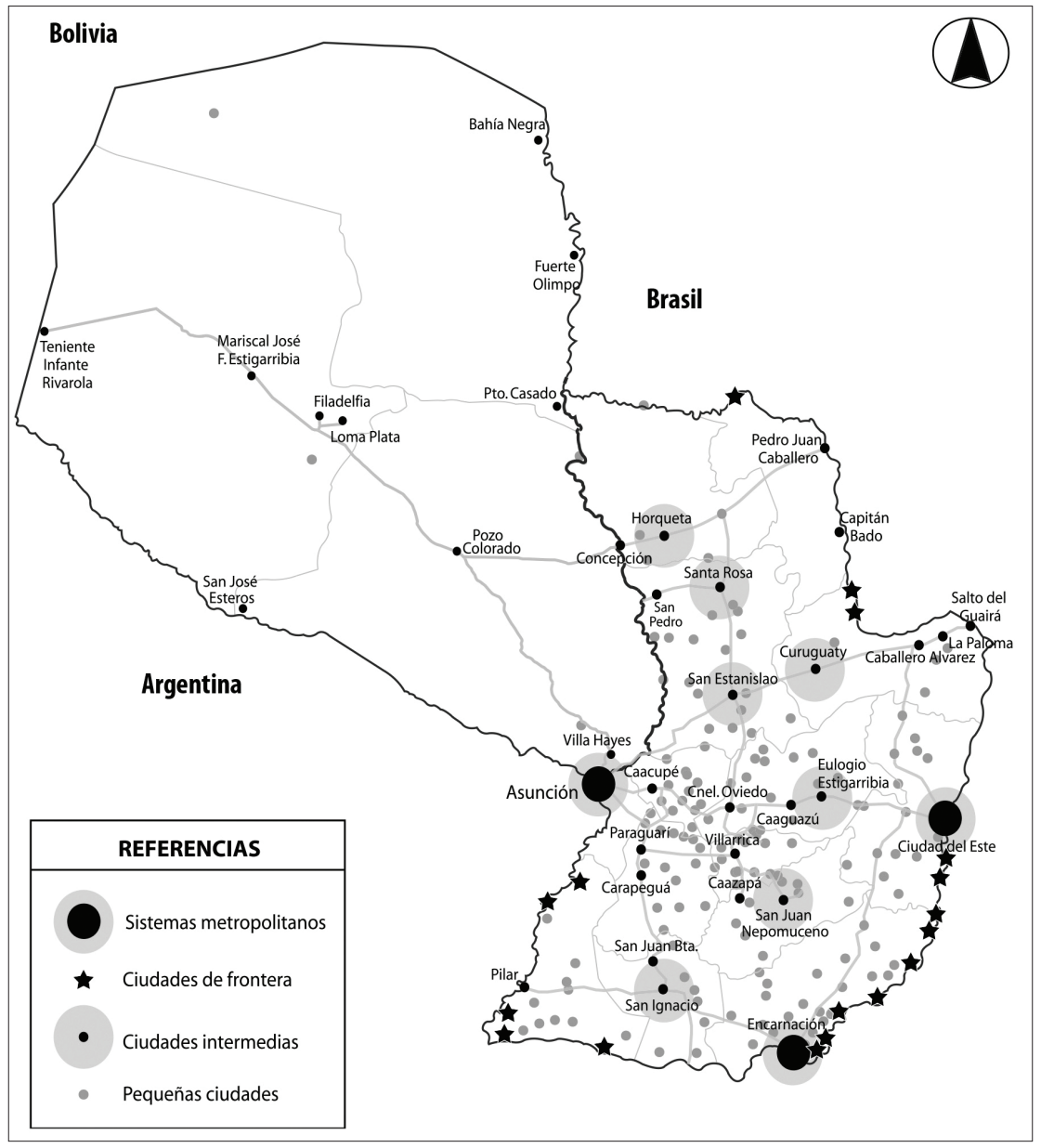

Fig. 3 - Tipologia de cidades paraguaias (Fonte: Vázquez, 2013).

Fig. 3 - Typology of Paraguayan cities (Source: Vázquez, 2013). 
conhecida como a "porta do Chaco". Tem como limites o rio Paraguai, na costa Ocidental; ao norte, o rio Verde; ao sul e a oeste, o distrito de Benjamín Aceval. Dados de 2015 da DGEEC estimavam uma população de 48.041 habitantes, sendo somente $40 \%$ desta população urbana. A densidade é de 1 hab. $/ \mathrm{km}^{2}$, uma das mais baixas do país. Como noutras cidades do Chaco, a sua economia é condicionada e nutrida pelo dinamismo da capital - sua proximidade com Assunção, que está distante a somente trinta quilômetros (fig. 4), a converte em parte da extensão metropolitana -, o que faz com que Vázquez (2010, p. 255), ironicamente, a caracterize como uma das possessōes da "coroa metropolitana de Assunção"e a nomeie "cidade do Chaco assunceno". Atualmente, Villa Hayes concentra dezesseis indústrias

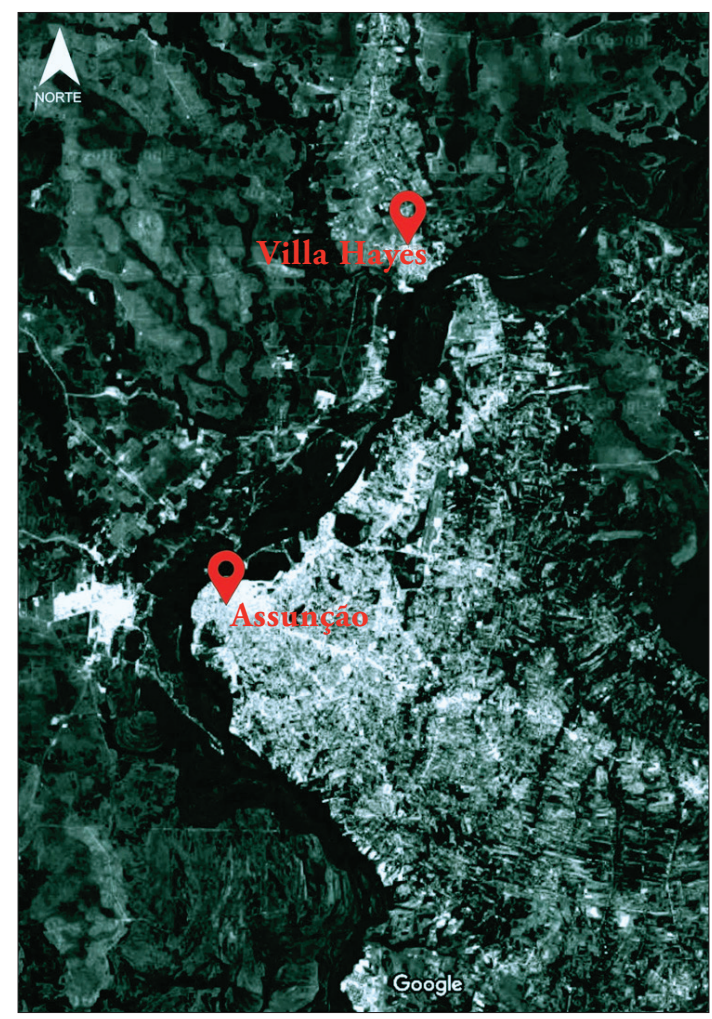

Fig. 4 - Localização de Assunção e Villa Hayes (Fonte: elaboração própria sobre base Google Maps).

Fig. 4 - Location of Asunción and Villa Hayes (Source: own elaboration based on Google Maps). 
de grande porte - nacionais e estrangeiras -, de diferentes atividades: extrativas de recursos naturais, cimenteiras, refrigeradoras, metalúrgicas, entre outras (ver as fig.s 5 e 6; ver Quadros II e II). Essas indústrias resultaram do avanço, no Paraguai, de alguns setores industriais - alimentar, têxtil, químico, metalúrgico e farmacêutico - a partir de 2003, quando a economia do país começou a crescer mais rapidamente, devido ao aumento da procura mundial de certas mercadorias, combinado com preços elevados e clima favorável. Assim, alguns departamentos como Presidente Hayes, San Pedro, Cordillera e Caaguazú, por exemplo - passaram a abrigar mais indústrias, muitas delas limitadas a transformaçôes simples dos produtos agropecuários.

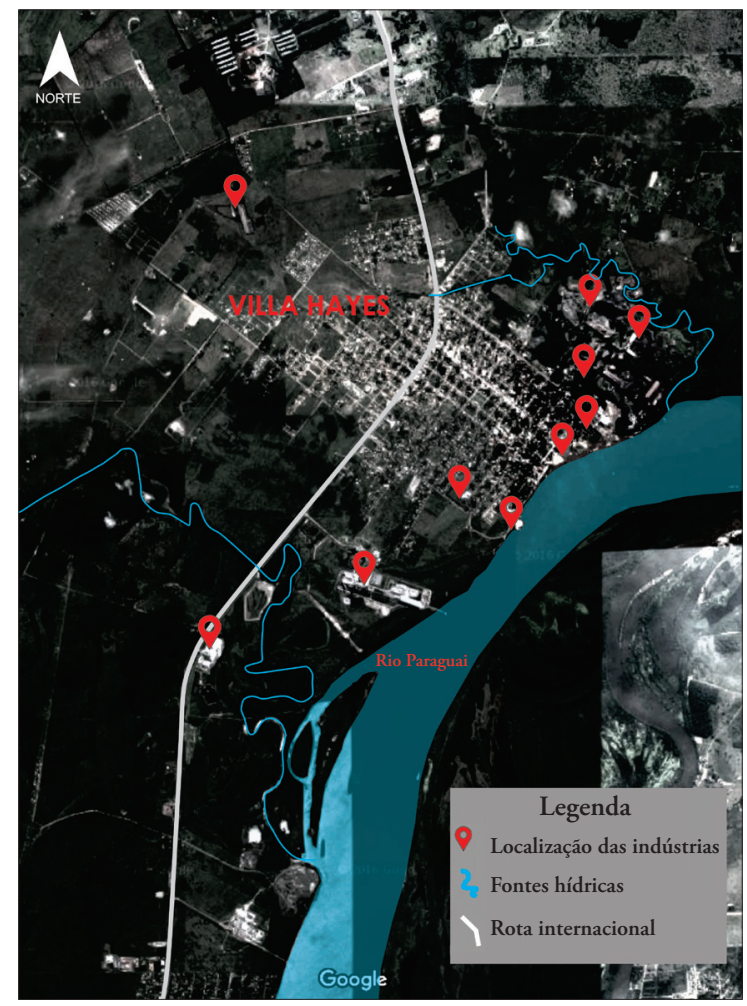

Fig. 5 - Localização de indústrias em Villa Hayes (Fonte: elaboração própria sobre base Google Maps).

Fig. 5 - Location of industries in Villa Hayes (Source: own elaboration based on Google Maps). 
É mais que importante dizer, contudo, que ainda que essas indústrias de Villa Hayes representem fonte de trabalho para parte de sua populaçáo, também trazem impactos ambientais e sociais, na qualidade de vida e na saúde da populaçáo mais próxima aos locais onde estão implantadas - majoritariamente zonas periféricas do

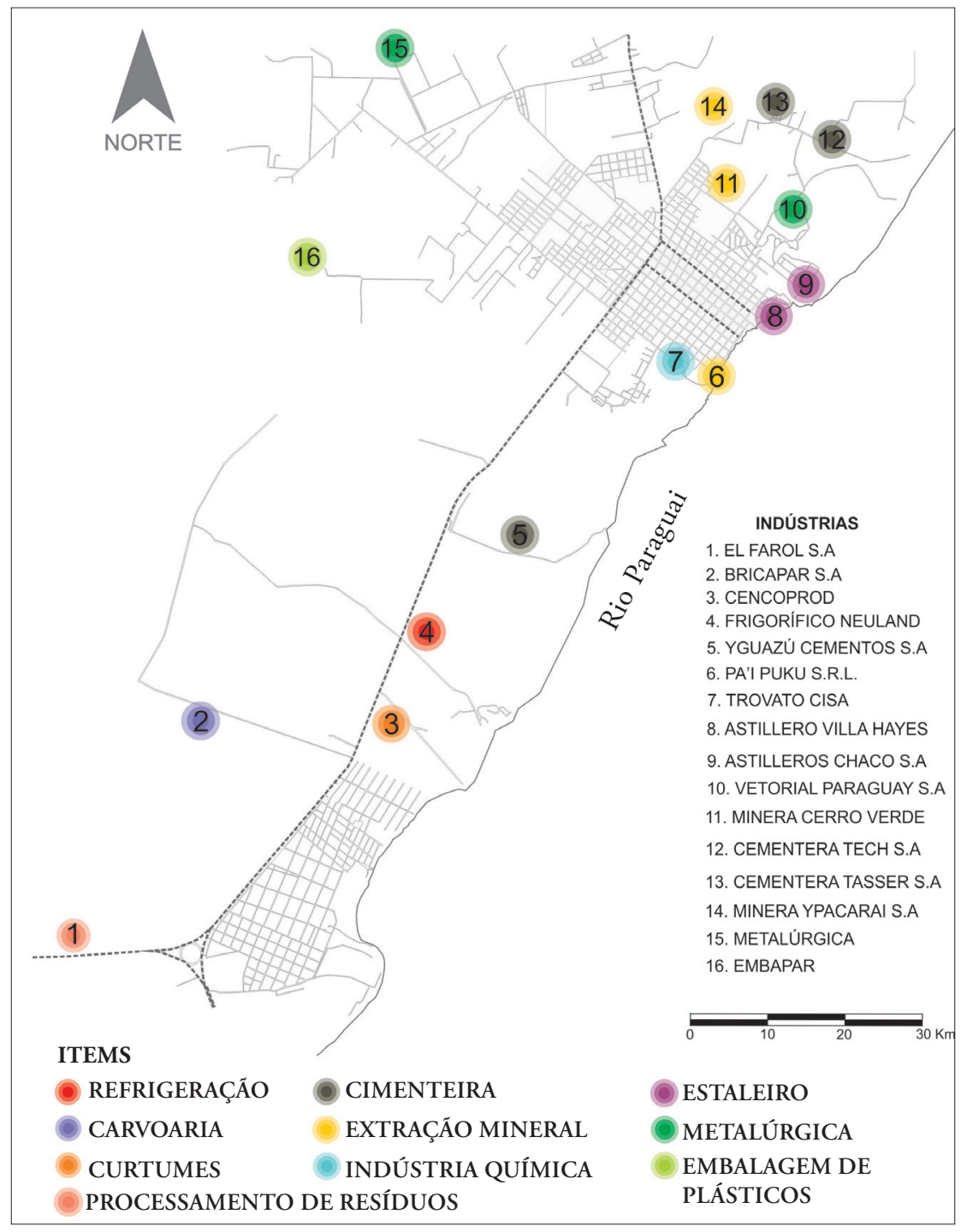

Fig. 6 - Localização de indústrias em Villa Hayes e suas respectivas atividades.

Fig. 6 - Location of industries in Villa Hayes and their activities. 
QUADRO I - Indústrias e atividades extrativas em Villa Hayes implantadas entre 1986 e 2015, por setor, empresa e quantidade.

BOARD I - Industries and extractive activities in Villa Hayes implemented between 1986 and 2015, by sector, company and number.

\begin{tabular}{|l|l|l|}
\hline Setor & Empresas & $\begin{array}{l}\text { Quantidade } \\
\text { de unidades } \\
\text { fabris }\end{array}$ \\
\hline Cimenteiras & $\begin{array}{l}\text { Yguazu Cementos S.A., Cementera Tech S.A., } \\
\text { Cementera Tesser S.A. }\end{array}$ & 3 \\
\hline Estaleiros & Astilleros Villa Hayes, Astilleros Chacos S.A. & 2 \\
\hline Refrigeraçáo & Cencoprod & 1 \\
\hline Extraçáo de minerais & $\begin{array}{l}\text { Pai'puku S.R.L., Minera Cerro Verde, Minera } \\
\text { Ypacarai S.A. }\end{array}$ & 3 \\
\hline Metalúrgicas & Vetorial Paraguay, Metalúrgica & 2 \\
\hline Carvoaria & Bricapar S.A. & 1 \\
\hline Curtume & Frigorífico Neuland & 1 \\
\hline $\begin{array}{l}\text { Processadora de resí- } \\
\text { duos }\end{array}$ & $\begin{array}{l}\text { El Farol S.A. - Processadora de Resíduos Sólidos e e } \\
\text { Domiciliários }\end{array}$ & 1 \\
\hline Indústria química & Trovato Cisa & 1 \\
\hline Moldes de plásticos & Embapar & 1 \\
\hline Total & & 16 \\
\hline
\end{tabular}

Fonte: elaboração própria, baseada em dados da Municipalidade de Villa Hayes. Source: own elaboration (2017), based on data from the Municipality of Villa Hayes and Porto.

centro urbano. É evidente a periculosidade destas atividades, mas nem o Estado tem exigido nem as empresas apresentado estudos sobre os possíveis danos causados, nem tấo pouco sobre os riscos à saúde dos seus trabalhadores e demais habitantes da região. Muitos fatores podem contribuir para que isto ocorra, como o poder econômico e a influência das empresas, a pouca visibilidade das pessoas afetadas, a debilidade ou ausência de políticas públicas ambientais e um baixo controle por normas do planejamento físico-territorial.

Convém trazer à discussão uma recente notificação da Comissão Econômica para a América Latina e o Caribe (CEPAL), que afirma que os investimentos de empresas transnacionais estrangeiras aumentaram durante a última década na maioria dos países dos subcontinente latino-americano (CEPAL, 2015). 
QUADRO II - Indústrias em Villa Hayes implantadas entre 1986 e 2015, por setor e impacto ambiental.

BOARD II - Industries in Villa Hayes deployed between 1986 and 2015, by sector and environmental impact.

\begin{tabular}{|l|l|}
\hline Setor & Riscos e possíveis danos \\
\hline Cimenteiras & $\begin{array}{l}\text { emissóes de partículas na atmosfera; } \\
\text { contaminantes hídricos em derrames de material e processos de } \\
\text { esfriamento. }\end{array}$ \\
\hline Refrigeração e curtume & $\begin{array}{l}\text { emissão de gases atmosféricos, grande quantidade de uso de água. } \\
\text { se os dejetos não recebem um adequado tratamento, existe a } \\
\text { possibilidade de contaminaçáo de águas superficiais e freáticas. }\end{array}$ \\
\hline Extração de minerais & $\begin{array}{l}\text { erosão da terra pela contínua extração de minerais; } \\
\text { emissão de partículas no ar (monóxido de carbono, nitrogênio, } \\
\text { partículas muito finas). }\end{array}$ \\
\hline Metalúrgicas e estaleiros & $\begin{array}{l}\text { degradação nas áreas de mineração; } \\
\text { - contaminação atmosférica nas proximidades da indústria. }\end{array}$ \\
\hline Carvoaria & $\begin{array}{l}\text { emissão de dióxido de carbono. } \\
\text { alteração da cobertura vegetal da zona, do habitat natural da fauna. }\end{array}$ \\
\hline Processadora de resíduos & produção constante de lixiviados. \\
\hline Indústria química & área de risco de incidentes químicos. \\
\hline
\end{tabular}

Fonte: elaboração própria (2017), com base em dados da Municipalidade de Villa Hayes e em Porto (2007). Source: own elaboration (2017), based on data from the Municipality of Villa Hayes and Porto (2007).

O documento também nos informa que as atividades industriais e extrativas das empresas de capitais externos, preferencialmente ocorrem nos países com escassa regulação ambiental e laboral, diminuindo assim as possibilidades de penalizaçáo em casos de danos no meio ambiente ou excessiva exploração do trabalho. Ainda há, nessa lógica, um efeito dominó: os deslocamentos de empreendimentos costumam ocorrer na direção de países com maior disponibilidade de recursos naturais para serem explorados, por sua vez ameaçados por processos de expansão territorial e exploração mercantil.

De notar, que nem todas as empresas em Villa Hayes são de capital estrangeiro. A lógica dos grandes grupos empresariais, seja qual for sua nacionalidade, é a mesma. Assim, estamos convencidos de que Villa Hayes exemplifica o fato de que os países em desenvolvimento, ao serem deliberadamente escolhidos para abrigar atividades 
contaminantes devido a leis ou sançôes mais brandas, constituem-se como zonas de sacrifício em escala internacional. A situação na capital distrital também esclarece que o fenômeno se repete na escala inter-regional, com a crescente concentração de empresas - estrangeiras ou nacionais - que mais do que brindar a região com vantagens, é na verdade à custa de ameaças ao meio ambiente e à saúde da população, que prefere servir aos interesses dos grupos econômicos mais abastados, geralmente ligados à capital.

Nesse sentido, uma notícia recentemente publicada no diário nacional $A B C$ Color apontou Villa Hayes como a cidade mais contaminada do país. Segundo a publicação, a localidade

"[...] se converteu em uma das mais contaminadas de nosso pais [Paraguai]. Nela estão assentadas várias fábricas que representam uma bomba-relógio para seus habitantes, devido a que diariamente aumentam as pessoas doentes, afetadas pelos efeitos da contaminaçâo ambiental" (Gallegos, 2016).

Outar denúncia, um pouco mais antiga, aponta uma das cimenteiras implantadas na cidade como a responsável por emitir poeiras tóxicas em horários noturnos, evitando assim que a situaçáo seja percebida pelos moradores. Por conta desta contaminação, segundo a publicação,

"[...] apareceram peixes mortos de diferentes espécies, o que, segundo os pescadores do lugar, constitui um grave retrocesso na proteção das espécies de peixes e também reduz tremendamente a possibilidade de trabalho e sustento das familias chaquenhas que se dedicam a esta atividade. Informada por profissionais médicos do hospital regional e distrital, a aparição de diversas enfermidades na população se deve à contaminação provocada por esta empresa, e outras que estão instaladas na zona do baixo Chaco".

Uma situação que exemplifica bem a debilidade dos controles legais é o processo de licença ambiental. No Paraguai, é a Secretaria do Ambiente (SEAM) a principal instituição nacional encarregada da formulação, coordenação, execução e 
fiscalização da política ambiental. Ao nível dos departamentos regionais, também existem secretarias de ambiente com objetivos semelhantes, aplicados à sua escala de atuação. Nos seus processos de licença e aprovação de projetos industriais, ambas exigem o Estudo de Impacto Ambiental (EIA) e o Relatório de Impacto Ambiental (RIMA), instrumentos estes para a verificação de aspectos positivos e negativos implicados na instalaçáo de empreendimentos, equipamentos e instalaçóes num determinado local, também comuns em outros países. E se muitas das empresas aqui citadas apresentaram tais documentos, os riscos e danos permanecem: em fevereiro de 2012, um periódico (Paraguay.com, 2012) denunciou que, ainda que fosse constante uma espessa cortina de fumo avermelhada proveniente das caldeiras da empresa Aceros del Paraguay - ACEPAR, a empresa ainda se mantinha funcionando sem ter em dia sua licença ambiental.

Também é importante ressaltar a localização de algumas destas indústrias em Villa Hayes e a sua relação com a lei nacional n. 3.239 (Paraguai, 2007), que versa sobre os recursos hídricos. Trata-se de uma norma que estabelece que, junto às margens dos rios urbanos, deve-se conservar uma faixa de cento e cinco metros de largura (cem de proteção, cinco para uso público). O objetivo é tanto proteger as matas ciliares como as vidas das pessoas em caso de inundação. Não obstante, a maioria das indústrias implantadas na orla do rio Paraguai náo cumprem este afastamento (ver fig. 7, que mostra um detalhe das indústrias 6, 7, 8 e 9 da fig. 6), sendo que alguma delas estáo a menos de trinta metros do rio - o que póe em evidência a debilidade da aplicaçáo da lei quando contra interesses privados.

Ante tal situação, estamos convencidos que as zonas de sacrifício também se manifestam na escala intraurbana de Villa Hayes, mais especificamente ao longo das margens do rio Paraguai e suas proximidades, onde se concentram as indústrias da cidade.

No que diz respeito à baixa visibilização das pessoas submetidas aos riscos, convém apresentar alguns dados da DGEEC. Infelizmente à escala da capital do departamento regional, somente se encontram informaçóes referente ao ano de 2003, das quais coletamos dados sobre rendimentos mensais e pobreza, comparando-os com aqueles referentes aos departamentos regionais de Presidente Hayes e de Assunção (TABELA I). Neles observa-se que, naquele momento, Villa 


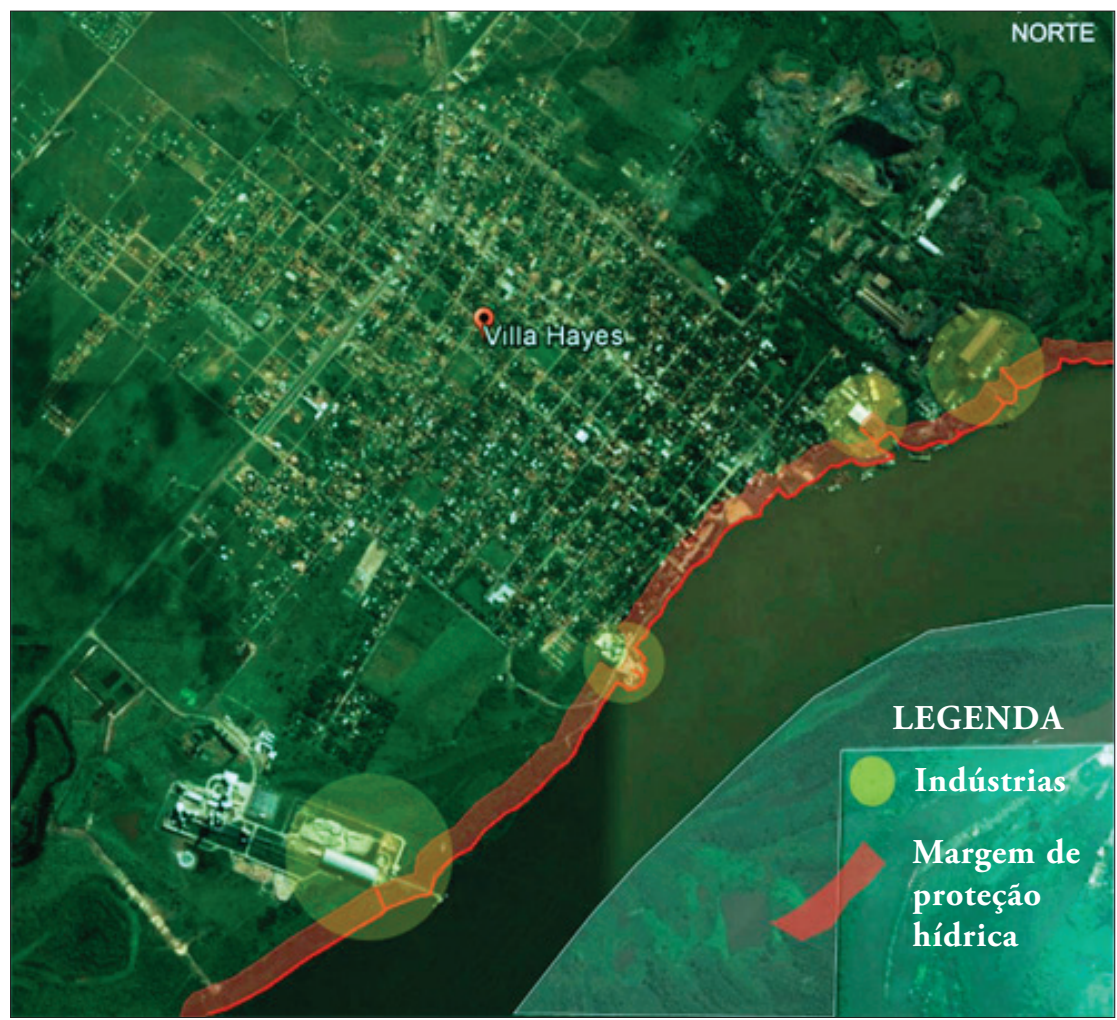

Fig. 7 - Localização das indústrias em Villa Hayes em relação à faixa de proteção do rio Paraguai (Fonte: elaboração própria sobre base Google Maps, 2016).

Fig. 7 - Location of the industries in Villa Hayes in relation to the protection strip of the Paraguay river (Source: own elaboration based on Google Maps, 2016).

Hayes apresentava níveis de pobreza muito semelhantes aos de Assunção, ambos por sua vez menos severos que os encontrados à escala do país.

Estariam estes dados nos indicando certa continuidade dos padróes de vida - e, possivelmente urbanos e ambientais - ao longo da mancha urbana estendida desde a capital nacional até à do departamento regional? Cremos que não, e isso parece desconfigurar-se de duas maneiras.

Por um lado, na mesma TABela I se pode observar que, em 2003, ainda que o rendimento médio mensal em Villa Hayes fosse um pouco mais alto que a média nacional, era cerca de $12 \%$ mais baixo que a média paga em todo o Departamento 
TABELA I - Rendimento médio mensal e medida de pobreza total em 2003, por distrito, departamento e país.

TABLE I - Average monthly income and measure of total poverty in 2003, by district, department and country.

\begin{tabular}{|c|c|c|c|c|c|}
\hline \multirow[b]{2}{*}{$\begin{array}{l}\text { Território/ } \\
\text { Informaçáo } \\
\text { recolhida }\end{array}$} & \multirow{2}{*}{$\begin{array}{c}\text { Rendimento médio } \\
\text { mensal (milhares de } \\
\text { guaranis/dólares) } \\
\text { A }\end{array}$} & \multicolumn{4}{|c|}{ Medida de pobreza total (\%) } \\
\hline & & $\begin{array}{c}\text { Incidência } \\
\text { da pobreza } \\
\text { B }\end{array}$ & $\begin{array}{c}\text { Intensidade } \\
\text { da pobreza } \\
\text { C }\end{array}$ & $\begin{array}{l}\text { Alcance } \\
\text { pobreza } \\
\text { D }\end{array}$ & $\begin{array}{c}\text { Severidade } \\
\text { da pobreza } \\
\text { E }\end{array}$ \\
\hline $\begin{array}{l}\text { Distrito Villa } \\
\text { Hayes }\end{array}$ & $750 / 128$ & $25,5 \mathrm{~F}$ & 36 & 9,4 & 4,8 \\
\hline $\begin{array}{l}\text { Departamento } \\
\text { Presidente Hayes }\end{array}$ & $853 / 145$ & $30,3 \mathrm{G}$ & 42,4 & 12,8 & 7,3 \\
\hline $\begin{array}{l}\text { Distrito Capital, } \\
\text { Assunçáo }\end{array}$ & $929 / 158$ & $24,8 \mathrm{H}$ & 37,0 & 9,2 & 4,7 \\
\hline País & $722 / 123$ & $41,4 \mathrm{I}$ & 42,3 & 17,5 & 9,8 \\
\hline
\end{tabular}

A. Cotação de 31/12/2003 (1.000 guaranis = 0,17 dólares), com arredondamento.

B. Proporçáo da população cujo rendimento per capta é inferior à linha de pobreza que, em consequência, mede a extensão ou a prevalência da pobreza. Indica quantos são os/as pobres.

C. É a média das distâncias relativa entre os rendimentos e a linha da pobreza (com distâncias dos/as nấo pobres igual a zero). Mede a profundidade da pobreza, isto é, indica quão pobres são os/as pobres.

D. Média das distâncias relativas entre os rendimentos dos/as pobres e a linha de pobreza (intensidade de pobreza), multiplicada pela incidência da pobreza.

E. É uma estimativa de disparidade, dando maiores pesos às distâncias relativas dos/as mais pobres que, em consequência, é uma medida da distribuição de rendiemntos entre os/as pobres. Indica quão diferentes são os/as pobres.

F. Infelizmente, os dados de 2003 são os mais recentemente compilados à escala do Distrito de Villa Hayes.

G. Em comparaçáo, os dados mais recentes de 2015 indicam uma incidência da pobreza no Departamento Villa Hayes de 20, $52 \%$.

H. Em comparação, os dados mais recentes de 2015 indicam uma incidência da pobreza em Assunção de $18,08 \%$.

I. Em comparação, os dados mais recentes de 2015 indicam uma incidência da pobreza em todo o país de $22,24 \%$.

Fonte: elaboração própria (2017), com base nos dados de Duarte et al. (2004) e DGEEC (2015). Source: own elaboration (2017), based on data of Duarte et al. (2004) and DGEEC (2015).

Presidente Hayes e cerca de $20 \%$ mais baixa que a média em Assunção. Por outro lado, a TABELA II revela outras importantes questóes acerca dos rendimentos mensais. Dados oficiais informam que a inflação acumulada no Paraguai entre 2003 e 2015 foi de 233 \%. Assim, aplicando-se uma simples correção, os rendimentos mensais seriam atualizados para cerca de 1.700 milhares de guaranis. Nesse sentido, pode-se notar que enquanto em 2015 as médias nacional e de Assunção entre os homens estavam acima desses valores - assim mostrando-se um aumento real da 
renda -, as mulheres de Presidente Hayes não somente recebiam rendimentos mensais mais baixos que as médias nacionais tanto de homens quanto de mulheres como também mais baixos que o valor atualizado pela inflação. Além disso, em uma comparação com Assunção, os homens de Presidente Hayes recebiam, segundo a TABELA II, rendimentos mensais $40 \%$ mais baixos. A mesma TABELA II ainda revela que, se bem que os dados de saúde de Presidente Hayes e Assunção equiparam-se, a população adulta de Presidente Hayes estuda cerca de quatro anos a menos que a população da capital. Adicionalmente, um número inferior a $20 \%$ da população de Presidente Hayes acessa a internet, somente a metade conta com rede de água e em seus lares praticamente não existe recolha de lixo e, sobretudo, a rede de esgoto sanitário - enquanto os dados de Assunção a este respeito são bem mais satisfatórios.

TABELA II - Rendimento médio mensal, anos de estudo, uso de internet e saúde da população em 2015, por sexo, país e departamento; e infraestruturas nos lares em 2015, por país e departamento.

TABLE II - Average monthly income, years of education, internet use and health of the population in 2015, by gender, country and department; and infrastructurelutility services in residential homes in 2015, by country and department.

\begin{tabular}{|l|l|l|l|}
\hline \multicolumn{1}{|c|}{ Informação recolhida } & \multicolumn{1}{|c|}{ País } & \multicolumn{1}{|c|}{$\begin{array}{c}\text { Dep. } \\
\text { Assunção }\end{array}$} & $\begin{array}{c}\text { Dep. Pres. } \\
\text { Hayes }\end{array}$ \\
\hline $\begin{array}{l}\text { Rendimento médio mensal de homens (milhares de } \\
\text { guaranis/dólaresA) }\end{array}$ & $2.476 / 421$ & $4.317 / 734$ & $2.699 / 459$ \\
\hline $\begin{array}{l}\text { Rendimento médio mensal de mulheres (milhares de } \\
\text { guaranis/dólaresA) }\end{array}$ & $1.826 / 310$ & $3.229 / 549$ & $1.661 / 282$ \\
\hline $\begin{array}{l}\text { Média de anos de estudo da população masculina de } \\
\text { 25 anos ou mais (\%). }\end{array}$ & 8,81 & 12,34 & 8,64 \\
\hline $\begin{array}{l}\text { Média de anos de estudo da população feminina de 25 } \\
\text { anos ou mais (\%). }\end{array}$ & 8,88 & 11,44 & 8,94 \\
\hline $\begin{array}{l}\text { População masculina de 10 anos ou mais que utiliza } \\
\text { a internet (\%) }\end{array}$ & 48,01 & 71,41 & 29,65 \\
\hline $\begin{array}{l}\text { População feminina de 10 anos ou mais que utiliza a } \\
\text { internet (\%) }\end{array}$ & 48,86 & 67,33 & 25,86 \\
\hline População masculina saudável (\%) & 68,32 & 78,71 & 75,83 \\
\hline População masculina saudável (\%) & 61,18 & 74,27 & 72,58 \\
\hline Lares com rede de esgoto sanitário (\%) & 12,28 & 70,49 & 0,30 \\
\hline Lares com rede de água (\%) & 81,40 & 97,73 & 50,07 \\
\hline Lares com coleta pública ou privada de lixo (\%) & 52,08 & 92,22 & 17,03 \\
\hline
\end{tabular}

A. Cotação de 31/12/2015 (1.000 guaranis = 0,17 dólares), com arredondamento.

Fonte: elaboração própria (2017), com base nos dados da DGEEC, 2015. Source: own elaboration (2017), based on data from DGEEC, 2015. 
Ainda que pela ausência de dados atuais especificamente sobre Villa Hayes não se possa dizer com plena certeza que a cidade possui as mesmas condiçôes avaliadas à escala departamental, mesmo assim soa impossível negar totalmente esta possibilidade. Os dados apresentados possibilitam-nos crer num delineamento de desigualdades em relação a Assunção em termos de educação e rendimento em especial no caso das mulheres -, infraestrutura e saneamento. Estas condições parecem facilitar, quer a implantação de usos sujos em Villa Hayes, quer reforçar, devido às vulnerabilidades populacionais, a ocorrência de riscos e danos.

\section{Conclusão}

Pretendemos, com este artigo e a partir do caso da cidade paraguaia de Vila Hayes, dar visibilidade a realidades hispano-americanas que lidam quotidianamente com injustiças ambientais e que, ainda que muito perversas perante as fragilidades económico-sociais dos estratos populacionais mais pobres a elas expostas, muitas vezes são ignoradas e recebem pouca atenção acadêmica - e que piora com a falta de legislação e fiscalização do Estado.

Até que ponto oferecer trabalho às custas de sacrificar a saúde e criar risco de morte a pessoas não é uma "chantagem ambiental" (Coelho et al., 2015)? Quer dizer, em que medida a implantação de empreendimentos ou atividades extremamente impactantes (e, por isso, ambientalmente inaceitáveis) somente ocorre porque são localizadas em áreas socialmente vulneráveis e mediante a promessa de postos de trabalho?

Villa Hayes continuará a expandir-se. Por isso, é indiscutível a importância de ações que lidem e tentem reduzir o panorama injusto que atravessa a cidade. Identificámos, no entanto, alguns dados que mostram que a implantação de tantas atividades industriais e extrativas (muito provavelmente legitimadas pelo imaginário de um desenvolvimento) além de gerar todo o tipo de riscos ambientais, aparentemente não vem oferecendo à população bem-estar e nem benefícios. Pelo contrário, ainda que muito próxima à capital paraguaia, Villa Hayes faz parte de um departamento regional que apresenta disparidades em temos de renda e acesso à infraestrutura e à educação, se comparados aos dados de Assunção. 
O ordenamento do território poderia ser uma das ferramentas capazes de prever a ocupação do território no sentido de garantir maior qualidade de vida aos cidadáos e o bom uso dos recursos naturais. Entretanto em Villa Hayes as leis que determinam o nível de proteção e o protagonismo do meio ambiente e da segurança das populaçóes parecem menos aplicáveis nos casos em que os interesses de setores e interesses econômicos se impóem ao bem comum. Assim, na medida em que, mesmo quando existentes, quaisquer leis não garantem a sua correta aplicação, mas ainda estamos convencidos que as injustiças ambientais não são criadas apenas por desatenção às normas ou devido à sua inexistência. $\mathrm{Na}$ verdade, uma ecologia política dos riscos industriais mostra, por um lado, que o progresso técnico e económico nem sempre ou, melhor dizendo, quase nunca - se converte em um "viver bem" das populaçóes. Por outro lado, as injustiças ambientais que inexoravelmente integram os projetos de desenvolvimento, priorizam a dimensão económica em detrimento da humana, e ocorrem porque é mais rentável ocupar o território dessa maneira (tecnologias efetivamente limpas são muito caras) e porque é oportuno pagar salários mais baixos para aqueles que deles desesperadamente necessitam.

Por outras palavras, na lógica da economia capitalista, existem territórios, corpos e vidas menos importantes e a riqueza de um pode significar a dor e a morte do outro, e a promessa de progresso futuro pode representar o sofrimento no presente.

\section{Bibliografia}

Acselrad, H., Mello, C. e Bezerra, G. (2009). O que é justiça ambiental. Rio de Janeiro, Garamond.

Borja, J. e Castells, M. (1998). Local y global: la gestión de las cindades en la era de la información. Madrid, Taurus.

Bullard, R. (1994). Dumping in dixie. San Francisco/Oxford, Westview Press.

CEPAL (2015). La inversión extranjera directa en América Latina y el Caribe. Santiago de Chile, Naciones Unidas.

Coelho, B. H. S., Loureiro, C. F., Irving, M. I. e Soares, D. G. (2015). Conflitos entre o Comperj e a gestão de áreas protegidas: o mosaico central fluminense como possibilidade de enfrentamento a impactos socioambientais de grandes empreendimentos industriais. Desenvolvimento e meio ambiente, n. 35, p. 259-273.

Da Silva, R. A. e Bueno, L. M. M. (2013). Injustiça urbana e ambiental: o planejamento de "zonas de sacrifício". Encontro Nacional da Associação Nacional de Pós-Graduação e Pesquisa em Planejamento Urbano e Regional, 15, 2013. Recife. Anais... Recife, ANPUR. 
De Souza, M. L. (2001). Mudar a cidade. Rio de Janeiro, Bertrand.

DGEEC (2015). Encuesta Permanente de Hogares. Asunción, Gobierno Nacional/DGEEC.

Duarte, F., N., Maciel, G., J. e Sosa de Servín, Z. C. (2004). Paraguay: pobreza y desigualdad a nivel distrital. Asunción, DGEEC/Fundo de la Mora.

Escobar, A. ([1995] 2007). La invención del Tercer Mundo. Caracas, Fundación Editorial El perro y la rana.

Gallegos. A. (2008, 2 de novembro). Villa Hayes es la ciudad más contaminada del país. ABC Color. http://www.abc.com.py/edicion-impresa/interior/villa-hayes-es-la-ciudad-mas-contaminada-delpais-1117101.html. Acceso en: 20.01.2017.

Martínez-Alier, J. ([2002] 2007). O ecologismo dos pobres. São Paulo, Contexto.

Moreno, C. (2013). Las ropas verdes del rey. La economía verde: una nueva fuente de acumulación primitiva. In Grupo Permanente de Trabajo Sobre Alternativas Al Desarrollo (Ed.), Alternativas al capitalismo/colonialismo del siglo XXI, p. 63-97. Buenos Aires, América Libre.

Name, L. y Bueno, L. M. M. (2013). Contradição nas cidades brasileiras: ambientalização do discurso do planejamento com permanência dos riscos. In L.F Lourenço e M.A. Mateus (Eds.). Riscos naturais, antrópicos e mistos, p. 727-739. Coimbra, Universidade de Coimbra.

Novaes, P. (2010). Uma estratégia chamada planejamento estratégico. Rio de Janeiro, 7Letras.

ONU. (1990, 14 de dezembro). Resolución 45/94: Necesidad de asegurar um medioambiente sano para el bienestar de las personas. Sesión Plenaria, 68.

Paraguay (2007, 10 de julho). Ley n. ${ }^{o}$ 3239/2007. De los recursos hídricos del Paraguay.

Paraguay.com (2012, 24 de fevereiro). SEAM interviene cementera de Villa Hayes por contaminación. Paraguay.com. http://www.paraguay.com/nacionales/seam-interviene-cementera-de-villa-hayes-por-contaminacion-80240. Acceso en: 20.01.2017.

Peralta, V. e Perrotta, M. (2004). Paraguay. Contexto económico, político y social: situación general del país. In T. Torres M. e N. Paredes H. (Eds.). Derecho a la salud: situación en países de América Latina. S.l., PIDHHD/ALAMES, p. 183-199.

Porto, M. F. S. (2007). Uma ecologia politica dos riscos. Rio de Janeiro, FIOCRUZ.

Svampa, M. e Viale, E. (2014). Maldesarrollo. Buenos Aires, Katz Editores.

Vásquez, F. (2010). Revolución urbana en el Chaco: las nuevas ciudades mundializadas del Paraguay. In A. Núñes, M.M. Padoin, e T.C.M. Oliveira (Eds.), Dilemas e diálogos platinos, p. 193-224. Dourados, Editora UFGD.

Vásquez, F. (2013). Ciudades intermedias y sustentabilidad urbana en Paraguay. In SOPLA - Programa Regional sobre Politicas Sociales (Ed.), El desafio del desarrollo sustentable en América Latina, p. 223243. Rio de Janeiro, Konrad-Adenauer-Stiftung.

Viégas, R. (2006). Desigualdade ambiental e zonas de sacrifício. In FASE e IPPUR (Eds.), Mapa dos conflitos ambientais no estado do Rio de Janeiro. Rio de Janeiro, FASE/IPPUR.

Villalba, N. (2012, 20 de junho). En Villa Hayes, Tasser continúa contaminando el medio ambiente. Tokeijuaa. http://tojeikuaa.blogspot.com.br/2012/06/en-villa-hayes-tasser-continua.html. Acceso en: 20.01.2017. 



\section{CONLUSÃO}

Fátima Velez de Castro

Departamento Geografia e Turismo, CEGOT e RISCOS, Universidade de Coimbra (Portugal) ORCID: 0000-0003-3927-0748 velezcastro@fl.uc.pt

Revisitando aqueles que foram os resultados dos trabalhos de investigação apresentados na obra "Pluralidade na diversidade dos riscos", pode-se concluir que os investigadores e os profissionais ligados à área dos riscos, estão cada vez mais conscientes para a crescente complexidade dos territórios, tanto do ponto de vista físico, como do ponto de vista humano. Já Luciano Lourenço (2015), na senda da discussão sobre a dimensão do pragmatismo e do risco ${ }^{1}$, referia:

"Por isso, se, como parece, o objetivo de muitos estudos for a mitigação do risco, então teremos de ser pragmáticos e considerar não só a fase da pré-catástrofe (...) que naturalmente deverá ser de preparaçāo, prevenção e previsão, mas também deverá ser tido em linha de conta o "durante", correspondente à fase de socorro (...) [e] a fase de pós-catástrofe, durante a qual será necessário reconstruir a área afetada" (Lourenço, 2015, p. 5).

No fundo, a multiplicidade de situaçóes quotidianas, leva a que de devam reequacionar procedimentos, assim como restruturar cenários de atuação. Um dos campos a repensar será o da dimensão formativa, com a atualização dos conteúdos e da prática letiva, assim como da cooperação entre entidades ligadas aos riscos e à proteção civil, no sentido de congregar esforços e criar sinergias, que permitam respostas mais rápidas e eficazes.

Além disso, é fundamental estar alerta e alertar para as alteraçóes ambientais. Nesta obra, chama-se a atenção para o fato de, por exemplo, as alteraçóes dos níveis de pluviosidade em determinadas regióes, poderem contribuir para significativas

\footnotetext{
${ }^{1}$ Lourenço, L. (2015). Risco, perigo e crise: pragmatismo e contextualização. In Siqueira, A., Valêncio, N., Siena, M. e Malagoli, M.A., Riscos de desastres relacionados à água. São Paulo: RiMa Editora.
} 
alteraçôes dos sistemas económicos e produtivos, criando fragilidades sociais tendencialmente estruturais. Por outro lado, é necessário alertar os governos locais para situaçôes de perigosidade ligadas a fenómenos excepcionai de diferente escala de afetação, quer no que diz respeito aos de rápida atuação (exemplo de precipitação intensa), como os de lenta progressáo (por exemplo, o caso dos períodos de seca). Neste contexto, também é necessário alertar para a dimensão do ordenamento do território, e da forma como a construçáo habitacional e funcional pode gerar situaçôes de perigo iminente em situação de risco natural.

Chamar a atenção para estas e outras situaçóes, parece ser uma preocupação constante em todos os estudos apresentados nesta obra e, em geral, para toda a comunidade académica. Comunicar ciência, transpor o fosso que muitas vezes existe entre os cientistas e a comunidade civil, transferir o conhecimento, nem sempre é uma tarefa fácil e óbvia. Mas é necessária e cada vez mais urgente, para que os estudos científicos possam ser de/sobre/para a sociedade.

Nesta lógica, sugere-se uma possibilidade de comunicação através da música, seja como mecanismo de catarse para os afetados (por exemplo, por stress pós-traumático), seja por canal de divulgação de práticas e de comportamentos a adotar (por exemplo, em campanhas de prevenção). Além disso, o contexto escolar educativo, também virá reforçar esta perspetiva através da psicoeducação, educando e difundindo conhecimento para a população escolar e para a sociedade em geral.

Mas haverá mais para fazer no campo dos riscos. Esperamos, pois, que os estudos cindínicos possam vir a ganhar um destaque cada vez mais evidente no quotidiano, continuando sempre na senda da prevenção, mitigaçẫo e promoção da segurança e do bem-estar das populaçōes, sobretudo dos mais vulneráveis. 


\section{SÉRIE \\ ESTUDOS CINDÍNICOS}

Títulos Publicados:

1 Incêndios em Estruturas. Aprender com o Passado;

2 Educação para a Redução dos Riscos;

3 Metodologia de Análise de Riscos através de Estudos de Casos;

4 Riscos Hidrometeorológicos;

5 Pluralidade na Diversidade de Riscos;

Tomos em preparação:

6 Risco Sísmico - Aprender com o Passado;

7 Geografia dos Incêndios Florestais. 50 anos de Incêndios a queimar Portugal;

8 Efeitos dos Incêndios Florestais nos Solos de Portugal;

9 Floresta, Incêndios e Educação;

10 Redução do Risco e Educação. 


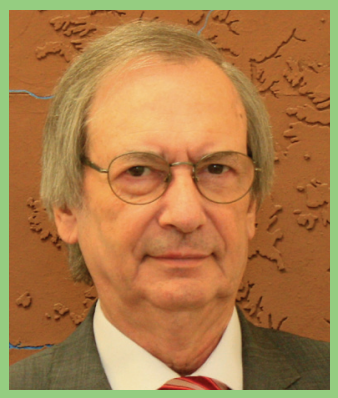

Luciano Lourenço é doutorado em Geografia Física, pela Universidade de Coimbra, onde é Professor Catedrático.

É Diretor do NICIF - Núcleo de Investigação Científica de Incêndios Florestais, da Faculdade de Letras da Universidade de Coimbra e Presidente da Direção da RISCOS - Associação Portuguesa de Riscos, Prevenção e Segurança.

Exerceu funções de Diretor-Geral da Agência para a Prevenção de Incêndios Florestais, Presidente do Conselho Geral da Escola Nacional de Bombeiros e Presidente da Direção da Escola Nacional de Bombeiros.

Consultor científico de vários organismos e de diversas revistas científicas, nacionais e estrangeiras, coordenou diversos projetos de investigação científica, nacionais e internacionais, e publicou mais de mais de três centenas de títulos, entre livros e capítulos de livro, artigos em revistas e atas de colóquios, nacionais e internacionais.

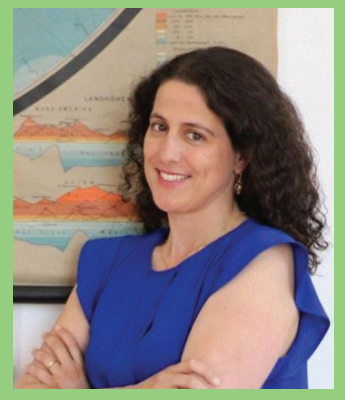

Fátima Velez de Castro é licenciada em Geografia (especialização em ensino), mestre em Estudos sobre a Europa e doutora em Geografia.

É Coordenadora do Mestrado em Ensino da Geografia no $3^{\circ}$ Ciclo e Ensino Secundário (FLUC); Coordenadora do Conselho de Formação de Professores da mesma instituição; membro da Comissão Científica do Departamento de Geografia e Turismo da Faculdade de Letras da Universidade de Coimbra; membro integrado do CEGOT (Centro de Estudos de Geografia e Ordenamento do Território).

É Tesoureira da RISCOS - Associação Portuguesa de Riscos, Prevenção e Segurança.

Foi Sub-Diretora do Curso de $10^{\circ}$ Ciclo (Licenciatura) em Geografia; membro do Conselho Pedagógico da Faculdade de Letras da Universidade de Coimbra; coordenadora geral da Mobilidade da mesma instituição.

Tem cinco livros publicados (três da sua autoria e dois em co-autoria) e cerca de sessenta outras publicações (capítulos de livros, artigos científicos em revistas nacionais e internacionais, artigos em atas de congressos, etc.). 


\section{RISCOS \\ ASSOCIAÇÃO PORTUGUESA DE RISCOS, PREVENÇÃO \\ E SEGURANÇA}

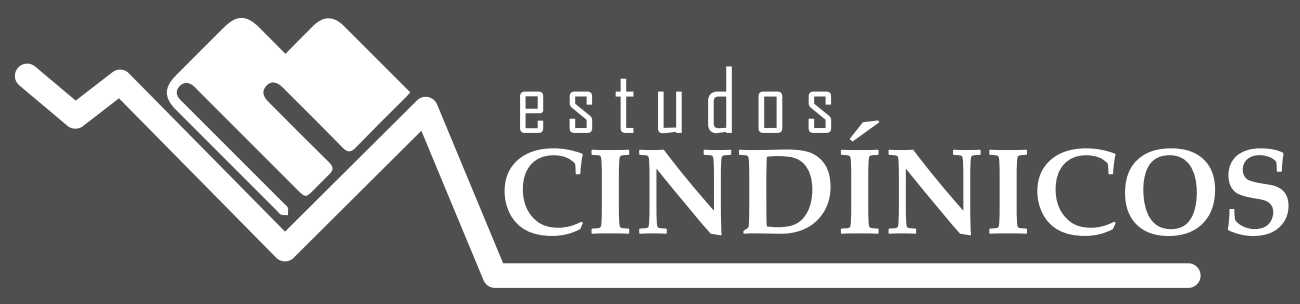

